\title{
Multiscale Electrochemical Investigation of the Corrosion Resistance of Various Alloys Used in Dental Prostheses
}

\author{
Sorin IACOBAN ${ }^{1}$, Daniel MARECI ${ }^{2}$, Georgiana BOLAT ${ }^{2,}$, Corneliu MUNTEANU ${ }^{1}$ and Ricardo \\ Manuel SOUTO ${ }^{3}$ \\ 1. Faculty of Materials Science and Engineering, \\ "Gheorghe Asachi” Technical University of Iasi, 700050 Iasi, Romania; \\ 2. Faculty of Chemical Engineering and Environmental Protection, \\ “Gheorghe Asachi” Technical University of Iasi, 700050 Iasi, Romania; \\ 3. Department of Chemistry, University of La Laguna, P.O. Box 456, E-38200 La Laguna (Tenerife, \\ Canary Islands), Spain
}

\begin{abstract}
The electrochemical behaviour of Ag-Pd (Paliag), Ni-Cr (Heraenium NA), and Co-Cr (Heraenium CE) alloys used in dental prosthetics construction of crowns and bridges was studied in $0.9 \% \mathrm{NaCl}$ solution at $25{ }^{\circ} \mathrm{C}$. The localized electrochemical characteristics related to corrosion resistance and eventual breakdown of the protecting oxide layers were investigated by scanning electrochemical microscopy (SECM), whereas potentiodynamic polarization and electrochemical impedance spectroscopy (EIS) techniques were employed to establish oxide stability. When the corrosion resistance of the alloys was evaluated by means of the corrosion current value determined around their corresponding open circuit potential in $0.9 \% \mathrm{NaCl}$ solution, good protection can be expected resulting from their spontaneous passivation (low current densities in the order of tenths of $\mu \mathrm{A}$ $\mathrm{cm}^{-2}$ ). The polarization resistance of all the samples increased with immersion time, in the sequence AgPd $<$ Heraenium NA < Heraenium CE. Yet, increased electrochemical activity was detected with SECM when the alloys were polarized at $+0.40 \mathrm{VSCE}$, a value that may be eventually experienced in the human body. Though a passivation mechanism was still operating in the chromium-containing alloys, oxide dissolution and precipitation of corrosion products occurred on Ag-Pd instead.
\end{abstract}

Keywords: Dental alloys; corrosion resistance; passivity; microelectrochemical characterization; SECM; EIS 


\section{INTRODUCTION}

Metals are more suitable than ceramics or polymeric materials for biomedical implantation in the case of load-bearing applications because they combine high mechanical strength and fracture toughness. ${ }^{[1-6]}$ Orthopaedists, clinicians and other investigators are thus seeking better metallic materials for applications in dental engineering. Unfortunately, metallic materials experience corrosion and wear processes in physiological environments, resulting in the release of toxic metallic ions that can originate various adverse tissue reactions and/or hypersensitivity reactions. ${ }^{[7]}$ Therefore, the study of the corrosion behavior and the degree of tolerance by tissues of the wide variety of dental alloy products commercially available -diverse in both their composition and their applications or performance- has been encouraged. In fact, corrosion resistance is a very important property for dental alloys. Corrosion of dental alloys in the oral environment not only results in the deterioration of the restoration, but also involves the release of metal ions that directly influences their biocompatibility. ${ }^{[8,9]}$

The corrosion resistance of metals and alloys is due to the spontaneous formation of a thin, compact layer of oxides named the passive layer. The chemical composition of the passive layers, their thickness and the degree of protection they can provide to the corresponding materials are related to a number of factors connected with the chemical environment, the composition and microstructure of the alloys, mechanical stresses, etc. Despite these differences, degradation occurs on biomaterials surfaces due to the chemical reactions between passive oxide layer and chloride ions present in the environment in which they are placed.

Ag-Pd alloys have been used in prosthetic dentistry in recent years because of their low price compared with gold, though they are more expensive than $\mathrm{Co}-\mathrm{Cr}$ or Ni-Cr alloys. Yet, the biological safety of Pd in dental alloys has become a matter of concern in recent years, motivated by reports on the frequent incidence of "Pd-allergy". ${ }^{[10]}$ Because of these problems, many practitioners use non-precious alloys such as $\mathrm{Ni}-\mathrm{Cr}$ or $\mathrm{Co}-\mathrm{Cr}$ instead. These alloys, thanks to their excellent properties, are frequently employed to manufacture crowns, bridge castings, and denture brasses. ${ }^{[11,12]} \mathrm{Ni}-\mathrm{Cr}$ and $\mathrm{Co}-\mathrm{Cr}$ alloys are known for their strength, hardness, and resistance to corrosion. Though $\mathrm{Ni}-\mathrm{Cr}$ alloys are quite popular for dental use, further investigation is required to establish the actual biocompatibility of $\mathrm{Ni}-\mathrm{Cr}$ alloys because $\mathrm{Ni}$ is the most allergenic metallic element known ${ }^{[5]}$ In this context, Reclaru et al. recently reported that biological tests did not show any cytotoxic effect on Hela and L929 cells or any change in TNF-alpha expression in monocytic cells during a study of 8 Ni-based alloys. ${ }^{[13]}$ So far, the main limitation to the use of Ni-containing objects in the human body has been imposed by the European Directive 2004/96/EC: "Piercing in the human Body". Though it directly affects those objects containing $\mathrm{Ni}$ that are intended for permanent contact with skin, it has established a limit of $0.2 \mu \mathrm{g} \mathrm{cm}^{-2}$ week in the rate at which nickel species can be released. ${ }^{[14]}$

The purpose of this study is to investigate the corrosion resistance of three commercial dental alloys (namely Ag-Pd, Co-Cr, and $\mathrm{Ni}-\mathrm{Cr}$ ) employed in dental crowns and bridges, by means of scanning electrochemical microscopy (SECM) to unveil local electrochemical activity in the protecting oxide layers related to their potential breakdown in the environment. Despite the rather recent development of the SECM technique, ${ }^{[15]}$ its unique combination of spatial resolution and electrochemical sensitivity in the micrometer range has provided valuable information on the electrochemical characterization of thin passive oxide layers covering numerous metals and alloys. ${ }^{[16]}$ Among them, a range of Ti-based implant materials have been examined by SECM to image electrochemical reactivity distributions related to heterogeneities in the growth of the oxide layers and potential precursor sites for oxide breakdown. ${ }^{[17-29]}$ A similar approach has been employed in this work to investigate Ag-Pd and two chromium-containing

alloys for the first time. The motivation of this work comes from a previous report from our group, ${ }^{[30]}$ 
where vitallium was regarded to be a potential alternative to Paliag based on conventional electrochemical techniques, because smaller corrosion currents were measured around the open circuit potential. Yet, the stability of the corresponding oxide layers under anodic polarization could not be satisfactorily established and different electrochemical behaviours were observed. The relevance of this observation should not be underestimated, because rather high anodic potential values have been recorded in the human body before. ${ }^{[31]}$ Experiments were performed in saline $0.9 \mathrm{wt} \% \mathrm{NaCl}$ solution $(\mathrm{pH}=6.7)$, equivalent to the saline average content in the human body fluids, ${ }^{[32,33]}$ in order to simulate aggressiveness of the oral environment. Next, since the intra-orally temperature fluctuates due to ingestion of hot or cold food and beverage, it is usually assumed that taking the environmental temperature (ca. $25^{\circ} \mathrm{C}$ ) in experimental settings is a reasonable approximation. ${ }^{[34]}$

\section{EXPERIMENTAL}

Three alloys employed in dental prosthetics construction for crowns and bridges were selected for this study. The materials and their suppliers were: Ag-Pd alloy - Paliag (J.F. Jelenko \& Co., Armonk, NY, USA), Ni-Cr alloy - Heraenium NA (Heraeus Kulzer GmbH, Hanau, Germany), and Co-Cr alloy Heraenium CE (Heraeus Kulzer GmbH, Hanau, Germany). The chemical composition of these alloys was established by Energy Dispersive Spectrometry (EDX) using a Quanta 3D AL99/D8229 instrument (FEI, Hillsboro, OR, USA) and it is given in Figure 1. The samples were cut to obtain a $0.95 \mathrm{~cm}^{2}$ flat surface, which was ground to a 2000 grit finish with SiC abrasive paper, followed by polishing step with $1 \mu \mathrm{m}$ alumina slurries. The resulting surfaces were degreased with ethyl alcohol, next sonicated in deionized water for cleaning, and dried under an air flow.

Electrochemical testing of the materials was performed in aerated 0.9 wt.\% $\mathrm{NaCl}$ solution at 25 ${ }^{\circ} \mathrm{C}$. Ultra-pure water was employed, and sodium chloride was analytical grade quality. The experimental set-up was a PARSTAT 4000 potentiostat (Princeton Applied Research, Oak Ridge, TN, USA) controlled by a personal computer and specific software (VersaStudio, PAR, Oak Ridge, TN, USA). A glass corrosion flow cell kit (C145/170, Radiometer Analytical, Lyon, France) with a platinum counterelectrode and a saturated calomel reference electrode (SCE) were used to perform the electrochemical measurements. ${ }^{[5]}$ The C145/170 is fitted with a PCTFE sample holder and a freely adjustable Luggin capillary. All potentials referred to in this article are with respect to SCE.

Measurement of linear potentiodynamic polarization curves (LPC) was initiated after stabilization of the open circuit potential in the $0.9 \mathrm{wt} \% \mathrm{NaCl}$ solution $(\mathrm{pH}=6.7)$. The tests were initiated from $0.25 \mathrm{~V}$ negative to the open circuit potential for each alloy in the environment, and subsequently scanned in the positive direction at $0.5 \mathrm{mV} \mathrm{s}^{-1}$ scan rate up to $+1.00 \mathrm{VscE}$. Once the linear potentiodynamic polarization curves were plotted, standard techniques were used to extract the zero current potential $\left(E_{\text {corr }}\right)$, and the corrosion current density $\left(j_{\text {corr }}\right)$, namely the application of Tafel analysis for a range of $\pm 100 \mathrm{mV}$ around the open circuit potential. From the measured potentiodynamic polarization curves, the passive current density (jpass) was determined too. All the polarization experiments were performed three times, to the reproducibility of the results obtained. The composition of the surface layers remaining on the dental alloys retrieved after potentiodynamic polarization testing was characterized by X-ray diffraction (XRD) using a Philips PW 1830/00 (Eindhoven, The Netherlands) diffractometer (CuK $\alpha_{1}$ radiation, 1.5406 Á wavelength).

Electrochemical impedance spectroscopy (EIS) was conducted at various polarization conditions of the samples by applying alternating potential signal amplitude of $\pm 10 \mathrm{mV}$ in the frequency range from $100 \mathrm{kHz}$ to $1 \mathrm{mHz}$. The experimental sequence was as it follows. First, EIS spectra were acquired at the 
open circuit potential attained by the samples after both 1 hour and 1 day immersion in 0.9 wt.\% $\mathrm{NaCl}$ solution. Next, the potential of the sample was set at $+0.4 \mathrm{VSCE}$ for $30 \mathrm{~min}$ before recording the EIS data of the polarized sample. The EIS experimental data were analyzed in terms of equivalent circuits (EC) using ZSimpWin software version 3.22. Impedance data were represented in Bode amplitude (logarithm of the impedance modulus as a function of the frequency logarithm) and phase (phase angle as a function of the frequency logarithm) plots. The advantage of this impedance graphs is that all the data measured over a wide frequency range can be displayed in one plot without overlapping. The frequency dependence of the phase angle readily indicates the number of time constants operating in the system.

Scanning electron microscope Quanta 200 (FEI, Hillsboro, OR, USA), operated at an accelerating voltage of $30 \mathrm{kV}$, together with EDX was used to study the surface morphology of the samples retrieved from the test solution after the electrochemical tests were completed.

A high-resolution SECM equipment supplied by Sensolytics (Bochum, Germany), was employed for spatially-resolved characterization of the electrochemical reactivity of the TiNbMo alloys. The instrument was built around a PalmSens (Utrecht, The Netherlands) electrochemical interface, all controlled with a personal computer. The alloy specimens were either tested at their open circuit potentials spontaneously developed in the saline solution, or polarized using the bipotentiostat built in the electrochemical interface. The specimens were mounted horizontally facing upwards at the bottom of a cell made of polytetrafluoroethene, which was equipped with an $\mathrm{Ag} / \mathrm{AgCl} /(3 \mathrm{M}) \mathrm{KCl}$ reference electrode and a platinum counter electrode. For the sake of consistency, potentials were subsequently referred to the standard calomel electrode by taking in account the potential difference between the two electrodes. The electrochemical cell was located inside a Faraday cage. Tip microelectrodes were made from $10 \mu \mathrm{m}$ dia. platinum wires sealed in glass. $0.5 \mathrm{mM}$ ferrocene-methanol was added to the $0.9 \mathrm{wt} . \%$ $\mathrm{NaCl}$ solution to act as electrochemical mediator at the tip. To enable the oxidation of ferrocenemethanol the tip was kept at a constant potential of $+0.46 \mathrm{~V}_{\mathrm{SCE}}{ }^{[26]}$ The micromanipulator stand of the SECM instrument was used to hold the microelectrode in place. The operating tip distance over the sample for SECM imaging was established by slowly approaching the surface of the alloy specimen with the tip and simultaneously recording the measured current at the microelectrode vs. $z$ displacement (i.e., z-approach curve). In our experiments the microelectrode was either stopped when the measured current decreased to $30 \%$ of the steady-state value in the bulk of the electrolyte, or when a current peak was detected while approaching the surface, and indication of mixed positive and negative feedback behaviours. Subsequently, the tip was withdrawn $10 \mu \mathrm{m}$ from the sample surface, and images were obtained by scanning the tip parallel to the sample surface (i.e., constant height operation). SECM images were recorded rastering an area of $250 \mu \mathrm{m}$ x $250 \mu \mathrm{m}$ using a scan rate of $30 \mu \mathrm{m} \mathrm{s}^{-1}$. Temperature control was not performed, and data were recorded at ambient temperature (ca. $22 \pm 3{ }^{\circ} \mathrm{C}$ )

\section{RESULTS AND DISCUSSION}

When an alloy is placed in the oral environment, an electrochemical interaction (i.e. corrosion process) between the alloy and the environment takes place. For a given environment, corrosion depends on the structure and composition of the alloy. ${ }^{[36]}$ The alloys of the present study have different chemical compositions.

\section{A. Scanning microelectrochemical characterization: surface reactivity of the passive films}

The electrochemical behaviour of the dental alloys at the micrometer scale was investigated by SECM operated in the feedback mode using a Pt microdisc electrode (UME). SECM images were 
acquired by rastering randomly distributed portions of the exposed surface of the material. The tip was operated at $10 \mu \mathrm{m}$ constant height. Tip potential was set at was set at +0.46 VSCE to ensure diffusional control for the reversible oxidation of ferrocene-methanol, a chemical that acted as the redox mediator when added to the $0.9 \mathrm{wt} . \% \mathrm{NaCl}$ test solution. The alloys were left unbiased, effectively at their corresponding open circuit potential in the electrolyte. The experimental sequence consisted in firstly measuring the $z$-approach curves at four different locations of the surface, by bringing the tip from the bulk electrolyte towards the surface while measuring the faradaic current flowing at the tip for ferrocene-methanol oxidation. This procedure also allowed correcting any eventual tilt of the substrate occurring during assembling of the small electrochemical cell used for the SECM measurements. Next, the tip was retracted to a tip-substrate distance equal to the diameter of the active area of the Pt disc ( $a=$ $10 \mu \mathrm{m})$ to measure electrochemical activity maps at constant height over a $250 \mu \mathrm{m}$ x $250 \mu \mathrm{m}$ area. Normalized current and distance values have been employed for easy comparison of the results, so every current value is referred to the limiting current measured in bulk solution, and distances are referred to the diameter of the platinum microdisc.

The spatial distribution of electrochemical activity of the three alloys immersed in the saline solution was recorded while they were unbiased, and subsequently polarized at +0.40 Vsce. This polarization value was chosen to account for the eventual development of positive potentials in the oral cavity. ${ }^{[37,38]}$ Figure 2 shows the SECM images obtained for the alloys at their corresponding $E_{\text {corr }}$ in the electrolyte. The spontaneous formation of insulating oxide layers on the surface of the alloys is observed in the images by recording very small normalized tip currents (close to zero). That is, the oxide-covered sample actually behaves as an insulator blocking the diffusion of the redox mediator towards the active are of the tip. As result, the amount of ferrocene-methanol available for oxidation is much smaller when the tip is placed in the proximity of the sample than when it is located in the bulk of the electrolyte. Since the measurements were initiated shortly after immersion of the samples in the solutions, some observations regarding the formation of the oxide layers on the materials can be obtained from the images. That is, higher tip currents were measured at the beginning of the scan, and they decreased steadily with the elapse of time due to oxide layer thickening. It is thus observed that oxide formation of Ag-Pd is faster, and normalized currents smaller than 0.1 were measured even at the beginning of the experiment, and the values only decreased very slightly for the remaining of the scan (cf. Figure 2C). Conversely, the tip currents measured on both Heraenium CE and NA are one order of magnitude bigger, and they show a steady decrease as the scan was recorded. Among them, the less insulating behaviour was monitored above Heraenium CE than over Heraenium NA (average tip currents around 0.79 and 0.56 , respectively). Longer times were required to attain tip current values similar to those measured for Paliag during the first scan (not shown here).

Major differences in electrochemical activity are observed when the samples polarized at +0.4 VSCE were imaged by feedback SECM as shown in Figure 3. The chromium-containing alloys are effectively protected at this polarization, and tip currents close to zero are measured over all the surface. Thick insulating oxide layers are formed in this electrolyte. Conversely, upon setting this polarization to Paliag, the surface becomes immediately activated, briefly displaying values greater than 1 at the beginning of the scan (see Figure 3C). This indicates that the metal surface is electrically conducting and it effectively supplies electrons to ferrocinium as to be reduced back to ferrocene. As result, a continuous regeneration of the redox mediator occurs in the small electrolyte volume comprised between the tip and the sample. Metal oxidation results in the system, and the subsequent decrease experienced by the tip currents as the scan further progresses must be related to the precipitation of corrosion products. In fact, some blocking effect to electron transfer results, though the new surface film 
is not as effective towards corrosion protection as the oxide film and the lowest tip current values recorded in the system are close to 0.2 .

In summary, SECM measurements supply evidences concerning a change of mechanism in the formation of surface layers on the dental alloys with anodic polarizations. Furthermore, differences in protection efficiency are readily monitored by scanning portions of the exposed metal surface.

\section{B. Electrochemical impedance spectroscopy}

Impedance spectra (Bode plots) for Paliag (Ag-Pd), Heraenium NA (Ni-Cr) and Heraenium CE (Co-Cr) alloys immersed in 0.9 wt. $\% ~ N a C l$ solution are shown in Figure 4. Spectra were measured at the open-circuit potential after various exposure times. In general, a longer exposure time in saline solution leads to a broadening of the phase angle plot consistent with the capacitive behaviour of the surface films, as well as the increase in the magnitude of the impedance at the low frequency limit. But the magnitude of these features greatly varies between the alloys, being minimum the change as a function of time for the Ag-Pd alloy, whereas the most notorious occurs for the Co-Cr alloy. The latter corresponds to the alloy exhibiting the slowest rate for oxide formation at the open circuit potential according to the feedback SECM images (cf. Figure 2).

From a cursory observation of the spectra it can be observed that they exhibit trends consistent with the formation of a passive oxide film on the surface of the three dental alloys as indicated by a phase angle greater than $-45^{\circ}$ over a certain frequency range. Yet, such dielectric behaviour extended over significantly wider frequency ranges in the case of the chromium-containing alloys, indicating that more sealing and less porous surface films were produced on them than on the Ag-Pd alloy. Next, all the alloys show a resistive behaviour at the low frequency limit, though the surface films formed on Ag-Pd were less resistive than for the other alloys.

Since any interface undergoing an electrochemical reaction is typically analogous to an electronic circuit consisting of a specific combination of resistors and capacitors, the electrochemical systems under the study can be described in terms of their equivalent circuit (EC). The EC that satisfied the above criteria were used to fit the experimental data and are presented in Figure 5A. It consists of the parallel combination terms $\left(R_{1} Q_{1}\right)$ in series with the resistance of the solution $\left(R_{\text {sol }}\right)$ occurring between the sample and the reference electrode. The parameters $R_{1}$ and $Q_{1}$ describe the properties of the surface films formed on these metallic materials, respectively the polarization resistance $\left(R_{1}\right)$ and capacitance of the passive layers $\left(Q_{1}\right)$. For fitting the spectra, a constant phase element (CPE) was used instead of a pure capacitance due to the distributed relaxation feature of the passive oxide films due to surface inhomogeneities (roughness and defects) present at the microscopic level. ${ }^{[3,39,40]}$ The impedance representation of CPE is given by:

$$
Z_{(C P E)}=\frac{1}{Y_{0}(j \omega)^{n}}
$$

where $\omega$ is the angular frequency and $Y_{0}$ is a constant, and the value of the exponent $n$, ranging $-1 \leq n \leq$ 1 , indicates the deviation from ideal capacitive behaviour (e.g., when $n \approx 1$ ). A very good correlation was obtained between EIS data using the proposed equivalent circuit and the experimental impedance spectra, and the fitting quality was established from the chi-squared $\left(\chi^{2}\right)$ values attained during data fitting, typically around $10^{-4}$, that correspond to an excellent agreement between the experimental data and the simulated values (see the good correspondence between the discrete point and the solid lines in Figure 4). The values of the parameters $\left(R_{1}, Q_{1}\right)$ obtained with the fitting procedure are listed in Table I.

High values of $R_{1}$ (greater than $10^{5} \Omega \mathrm{cm}^{2}$ ) are observed for all the samples, confirming the formation of surface layers on the materials that supply protection against corrosion in $0.9 \mathrm{wt} . \% \mathrm{NaCl}$ 
solution. The resistance, $R_{1}$, of the passive layer increases with the immersion time. These results seem to correspond to a thickening of the surface films formed on these dental alloys. The $R_{1}$ values obtained for the Ag-Pd alloy are generally smaller than those found for either Co-Cr or Ni-Cr alloys in the same electrolyte. After 1 hour immersion in the saline solution, the polarization resistance of the Co-Cr alloy (ca. $600 \mathrm{k} \Omega \mathrm{cm}^{2}$ ) is the largest of the three alloys, and it increases after 1 day (ca. $1.2 \mathrm{M} \Omega \mathrm{cm}^{2}$ ) indicating the high stability of Heraenium CE alloy in this solution related to passivation.

EIS measurements were also performed when the samples were polarized at $+0.4 \mathrm{VSCE}$ and the corresponding spectra are given in Figure 6. The Bode-phase plots show now the occurrence of two times constants for the three dental alloys when they were polarized at +0.4 VSCE in the aerated 0.9 wt. $\%$ $\mathrm{NaCl}$ solution. The two time constants appear as two maxima for the phase angles in each plot. Therefore, a different EC had to be considered for the simulation of the EIS data of the anodicallypolarized samples. Figure 5B exhibits the EC formed by a series combination of the $R_{\text {sol }}$ solution resistance, and with two $R Q$ elements in parallel: $R_{\mathrm{sol}}\left(R_{1} Q_{1}\right)\left(R_{2} Q_{2}\right)$. In the case of Co-Cr and $\mathrm{Ni}-\mathrm{Cr}$ alloys, $R_{1} / Q_{1}$ and $R_{2} / Q_{2}$ designate the low and high frequency time constant. $R_{1}$ and $Q_{1}$ correspond to the resistance and pseudo-capacitance of the passive layer, whereas $R_{2} / Q_{2}$ gives the resistance and pseudocapacitance of the charge transfer in the surface of the both $\mathrm{Co}-\mathrm{Cr}$ and $\mathrm{Ni}-\mathrm{Cr}$ alloys.

In the case of Ag-Pd alloy, the two relaxation time constants can be attributed to charge transfer reactions occurring at the interface between the bulk substrate and the precipitated corrosion products interface, and to between the corrosion products and the electrolytic phase. Table II lists the impedance parameters determined from the fits.

Therefore, two distinctive behaviours can be distinguished between these alloys from the comparison of the resistances of the surface layers measured with and without polarization. First, the resistances of the passive layers ( $R_{1}$ in Table I and $R_{2}$ in Table II, respectively) formed on Ni-Cr and CoCr alloys at +0.4 VSCE are bigger than those determined at the open circuit potential even after 1 day immersion in the aerated $0.9 \mathrm{wt} . \% \mathrm{NaCl}$ solution. The passivating nature of the films is evidenced in this way, accounting for the good corrosion resistance of the alloys. The effect of the anodic polarization is to thicken the oxide films on the surface of the alloys. Conversely, the very low resistance values measured in the case of Paliag alloy polarized at +0.4 V SCE reveals that the corrosion products do not effectively protect the materials from corrosion in the saline solution, and metal dissolution increases as the potential is made more positive. These results support the observations made in Section 3A from SECM data.

\section{Potentiodynamic polarization testing}

The stability of the oxide layers formed on the surface of the dental alloys was further investigated using potentiodynamic polarization. Figure 7 shows a comparison of potentiodynamic polarization curves of Ag-Pd, Ni-Cr and Co-Cr alloys in $0.9 \mathrm{wt} . \% \mathrm{NaCl}$ solution at $25^{\circ} \mathrm{C}$. The values of the corrosion potential $\left(E_{\text {corr }}\right)$ and the corrosion current density ( $\left.j_{\text {corr }}\right)$ for each material were determined using the dedicated CorrWare software electrochemical test system, and they are given in Table IV.

The direct comparison of the corrosion rates shows little discrimination between these alloys. In fact, the corrosion current densities of these dental alloys were small in all cases (i.e., below $1 \mu \mathrm{A} \mathrm{cm} \mathrm{cm}^{-2}$ ). Distinction is better accomplished by looking at the anodic branches of the potentiodynamic curves, as different trends can be observed for each material. In the case of the Ag-Pd alloy, the anodic current shows a monotonically increase as the polarization is made positive from the corrosion potential, without attaining a current plateau related to effective passivation of the metallic surface. The precipitation of AgCl may be evident by visual inspection, and should be noted the presence of chlorine 
on the surface of the retrieved sample that is determined by EDX (Figure 9C), that was not present before the experiments (see Figure 1C). However, this AgCl film cannot be regarded an efficient barrier to metal dissolution. ${ }^{[41]}$ The surface morphologies and composition of the Ag-Pd alloy retrieved from the 0.9 wt.\% $\mathrm{NaCl}$ solution after recording the potentiodynamic polarization curve are given in Figures 8C and 9C, respectively, and they confirm the electrochemical results. Additional experimental evidence was gathered by recording the X-ray diffractogram of the retrieved sample clearly displaying that most silver on the outer layer is oxidized and precipitated as AgCl (see Figure 10).

The polarization curve for the $\mathrm{Ni}-\mathrm{Cr}$ alloy in $0.9 \mathrm{wt} . \% \mathrm{NaCl}$ solution exhibited a similar trend. Though surface analysis indicated that a surface film compatible with an oxide passive layer was formed on the surface of Ni-Cr (Heraenium NA) as monitored after the polarization tests (cf. Figure 9A), apparently very similar in composition to the original air-formed layer present on the alloy prior to electrochemical testing (see Figure 1A). This layer was basically compact and uniform at the SEM micrograph in Figure 8A, the passive layer formed on this material was not an efficient barrier to dissolution, because the anodic current shows a monotonically increase near the corrosion potential. Though EDX data do not evidence a significant change in the chemical composition of the surface oxide layer due to electrochemical testing in saline solution (compare the spectra shown in Figures 1A and 9A), XRD data suggest that corrosion protection is almost exclusively exerted by $\mathrm{Cr}$ and Ni oxides (see Figure 10).

Conversely, the Co-Cr alloy (Heraenium CE) revealed a small active and large passive region. The current plateau related to passivation spans over $1 \mathrm{~V}$, and the onset of passive film breakdown occurs at potentials values in excess of $+0.7 \mathrm{VSCE}$. The passive current density amounts ca. $0.7 \mu \mathrm{A} \mathrm{cm}{ }^{2}$, a value typically corresponding to passive materials. In fact, the average anodic current density measured for Co-Cr alloy is significantly smaller than those observed for the Ni-Cr and Ag-Pd alloys. The formation of the passive film is confirmed by the SEM and EDX characterization (see Figures 8B and 9B), and it is composed by $\mathrm{CrO}$ and $\mathrm{Co}_{3} \mathrm{O}_{4}$ according to the $\mathrm{XRD}$ spectrum shown in Figure 10 for Heraenium CE.

\section{CONCLUSIONS}

Any metal/alloy that is to be used in oral environment is that it must not to produce corrosion products that could be harmful to the body. The degradation of metal /alloy should be limited in order to grantee its service life. Three alloys used in dental prosthetics construction for crowns and bridges, namely Ag-Pd, Ni-Cr and Co-Cr, were evaluated for in vitro electrochemical behaviour in 0.9 wt.\% $\mathrm{NaCl}$ solution. Using a multiscale electrochemical characterization procedure, it was consistently shown that these alloys offer a good corrosion resistance when left unbiased. The rather positive open circuit potential of Ag-Pd is attributed to dealloying followed by surface enrichment with Ag and the possible formation of an insoluble AgCl surface film on the respective alloy surfaces. The corrosion currents have values of a few tenths of $\mu \mathrm{A} \mathrm{cm} \mathrm{cm}^{-2}$ for all the samples. The EIS results show that all the alloys exhibit some degree of protection against corrosion at the open circuit potential, resulting from either the formation of passivating oxide layers or the precipitation of corrosion products on the surface of the materials. The polarization resistance obtained from EIS spectra increases with immersion time. Equivalent circuits that satisfactorily reproduce the trends of the impedance spectra were proposed to characterize the electrochemical stability of the studied dental alloys in $0.9 \mathrm{wt} . \% \mathrm{NaCl}$ solution. Finally, SECM images assisted identification of the different mechanisms involved in the formation of surface layers on these materials. 


\section{Acknowledgments}

This work was supported by a grant from the Romanian National Authority for Scientific Research, CNCS-UEFISCDI, project number PN-II-ID-PCE-2011-3-0218. Additional support from the Ministerio de Economía y Competitividad (MINECO, Madrid, Spain) and the European Regional Development Fund (Brussels, Belgium) under grant CTQ2012-36787 is acknowledged.

\section{References}

1. M.P. Staiger and A.M. Pietak: Biomaterials, 2006, vol. 27, pp.1728-34.

2. L.-J. Xu, S.-L- Xiao. J. Tian, Y.-Y. Chen and Y.-D. Huang: Trans. Nonferr. Metal. Soc., 2009, vol. 19, pp. s639-44.

3. L.-J. Xu, S.-L. Xiao, J. Tian and Y.-Y. Chen: Trans. Nonferr. Metal Soc., 2013, vol. 23, pp. 692-98.

4. P. Handzlik and K. Fitzner: Trans. Nonferr. Metal Soc., 2013, vol. 23, pp. 866-75.

5. V.S. Saji and H.-C. Choe: Trans. Nonferr. Metal Soc., 2009, vol. 19, pp. 785-90.

6. D. Mareci, R. Chelariu, G. Bolat, A. Cailean, V. Grancea and D. Sutiman: Trans. Nonferr. Metal Soc., 2013, vol. 23, pp. 3829-36.

7. K.L. Wapner: Clin. Orthop. Relat. Res., 1991, vol. 271, pp.12-20.

8. J.C. Wataha, R.G. Craig and C.T. Haks: J. Dent. Res., 1991, vol. 70, pp.1014-18.

9. J.C. Wataha, C.T. Haks and R.G. Craig: J. Biomed. Mater. Res., 1991, vol. 25, pp.1133-49.

10. N.K. Sarkar, D.W. Berzins and A. Prasad: Dent. Mater., 2000, vol. 16, pp. 374-9.

11. M. Sharma, A.V. Ramesh Kumar, N. Singh, N. Adya and B. Saluja: J. Mater. Eng. Perform., 2008, vol. 17, pp. 695-701.

12. H.F. Hildebrand, C. Veron and P. Martin: Biomaterials, 1989, vol. 10, pp. 545-8.

13. L. Reclaru, R.E. Unger, C.J. Kirkpatrick, C. Susz, P.-Y. Eschler, M.-H. Zuercher, I. Antoniac and H. Luthy: Mater. Sci. Eng. C, 2012, vol. 32, pp.1452-60.

14. Official J. Eur. Communities, 2004, vol. L301, pp. 51-2.

15. A.J. Bard, F.R.F. Fan and J. Kwak: Anal. Chem., 1989, vol. 61, pp. 132-8.

16. M.B. Jensen and D.E. Tallman, in: A.J. Bard and C.G. Zoski (Eds.): Electroanalytical Chemistry: A Series of Advances, vol. 24, CRC Press, Boca Raton, FL, 2012, pp. 171-286.

17. S.B. Basame and H.S. White, J. Phys. Chem., 1995, vol. 99, pp. 16430-5.

18. L.F. Garfias-Mesias, M. Alodan, P.I. James and W.H. Smyrl: J. Electrochem. Soc., 1998, vol. 145, pp. 2005-10.

19. S.B. Basame and H.S. White, J. Phys. Chem. B, 1998, vol. 102, pp. 9812-9.

20. K. Fushimi, T. Okawa, K. Azumi and M. Seo: J. Electrochem. Soc., 2000, vol. 147, pp. 524-9.

21. A. Schulte, S. Belger, M. Etienne and W. Schuhmann: Mater. Sci. Eng. A, 2004, vol. 378, pp. 523-6.

22. R.K. Zhu, C. Nowierski, Z.F. Ding, J.J. Noel and D.W. Shoesmith: Chem. Mater., 2007, vol. 19, pp. 2533-43.

23. S.E. Pust, D. Scharnweber, C.N. Kirchner and G. Wittstock: Adv. Mater., 2007, vol. 19, pp. $878-82$.

24. S.E. Pust, D. Scharnweber, S. Baunack and G. Wittstock: Adv. Mater., 2007, vol. 19, pp. 878-82

25. R.K. Zhu, Z.Q. Qin, J.J. Noel, D.W. Shoesmith and Z.F. Ding: J. Electrochem. Soc., 2008, vol. 154, pp. C508-14.

26. G. Ciurescu, J. Izquierdo, J.J. Santana, D. Mareci, D. Sutiman, S. González and R.M. Souto: Int. J. Electrochem. Sci., 2012, vol. 7, 7404-24.

27. G. Bolat, J. Izquierdo, J.J. Santana, D. Mareci and R.M. Souto: Electrochim. Acta, 2013, vol. 88, pp. 447-56. 
28. G. Bolat, D. Mareci, R. Chelariu, J. Izquierdo, S. González and R.M. Souto: Electrochim. Acta, 2013, vol. 103, pp. 470-80.

29. R. Chelariu, G. Bolat, J. Izquierdo, D. Mareci, D.M. Gordin, T. Gloriant, R.M. Souto: Electrochim. Acta, 2014, vol. 137, pp. 280-9.

30. D. Mareci, D. Sutiman, A. Cailean and G. Bolat: Bull. Mater. Sci., 2010, vol. 33, pp. 491-500.

31. G. Rondelli and B. Vincentini: Biomaterials, 2002, vol. 23, pp. 639-44.

32. K.J. Bundy, in: R. Baboian (Ed.): Corrosion Tests and Standards: Application and Interpretation, 2nd. edn., ASTM, Philadelphia, PA, 2005, p. 500.

33. S. L. Assis, S. Wolynec and I. Costa: Electrochim. Acta, 2006, vol. 51, pp. 1815-9.

34. G. Airoldi, G. Riva, M. Vanelli, V. Filippi, G. Garanttini, Oral environment temperature changes induced by cold/hot liquid intake, Am. J. Orthod. Dentofac. Orthop., 1997, vol. 112, pp. 58-63.

35. D. Mareci, I. Rusu, R. Chelariu, G. Bolat, C. Munteanu, D. Sutiman and R.M. Souto: Eur. J. Sci. Theol., 2013, vol. 9, pp. 189-99.

36. M. Geetha, U. Mudali Kamachi, A.K. Gogia, R. Asokamani and R. Baldev: Corros. Sci., 2004, vol. 46, pp. 877-92.

37. G.J. Ewers and E.H. Greener: J. Oral Rehab., 1985, vol. 12, pp. 469-76.

38. M.A. Ameer, E. Khamis and M. Al-Motlaq: Corros. Sci., 2004, vol. 46, pp. 2825-36.

39. J.R. Macdonald: Impedance Spectroscopy, Emphasizing Solid Materials and Systems, Wiley, New York, NY, 1987, p. 39.

40. X. Cheng and S.G. Roscoe: Biomaterials, 2005, vol. 26, pp. 7350-6.

41. N.K. Sarkar and E.H. Greener: J. Oral. Rehab., 1975, vol. 2, pp. 49-62.

Table I. Impedance parameters of the three dental alloys recorded at their open circuit potentials during exposure to aerated $0.9 \mathrm{wt} . \% \mathrm{NaCl}$ solution for different time durations.

\begin{tabular}{|l|c|c|c|c|}
\hline \multicolumn{1}{|c|}{ Dental alloy } & $\begin{array}{c}\text { Immersion } \\
\text { time } / \mathrm{h}\end{array}$ & $\begin{array}{c}10^{5} \mathrm{Q}_{1} / \\
\mathrm{S} \mathrm{cm}^{-2} \mathrm{~s}^{n}\end{array}$ & $n_{1}$ & $\begin{array}{c}R_{1} / \\
\mathrm{k} \Omega \mathrm{cm}^{2}\end{array}$ \\
\hline \multirow{2}{*}{ Heraenium NA } & 1 & 2.6 & 0.80 & 380 \\
\cline { 2 - 5 } & 24 & 2.1 & 0.81 & 720 \\
\hline \multirow{2}{*}{ Heraenium CE } & 1 & 2.3 & 0.81 & 580 \\
\cline { 2 - 5 } & 24 & 1.2 & 0.82 & 1220 \\
\hline \multirow{2}{*}{ Paliag } & 1 & 3.4 & 0.80 & 250 \\
\cline { 2 - 5 } & 24 & 2.8 & 0.81 & 320 \\
\hline
\end{tabular}


Table II. Impedance parameters of the three dental alloys polarized at +0.4 VSCE during exposure to aerated 0.9 wt. $\% \mathrm{NaCl}$ solution.

\begin{tabular}{|l|c|c|c|c|c|c|}
\hline \multicolumn{1}{|c|}{ Dental alloy } & $\begin{array}{c}10^{4} \mathrm{Q}_{1} / \\
\mathrm{S} \mathrm{cm}^{-2} \mathrm{~s}^{n}\end{array}$ & $n_{1}$ & $\begin{array}{c}R_{1} / \\
\mathrm{k} \Omega \mathrm{cm}^{2}\end{array}$ & $\begin{array}{c}10^{5} \mathrm{Q}_{2} / \\
\mathrm{S} \mathrm{cm}^{-2} \mathrm{~s}^{n}\end{array}$ & $n_{2}$ & $\begin{array}{c}R_{2} / \\
\mathrm{k} \Omega \mathrm{cm}^{2}\end{array}$ \\
\hline Heraenium NA & 0.7 & 0.78 & 15 & 2.4 & 0.81 & 650 \\
\hline Heraenium CE & 0.6 & 0.79 & 35 & 1.2 & 0.82 & 1150 \\
\hline Paliag & 2.7 & 0.69 & 0.3 & 9.8 & 0.75 & 1.5 \\
\hline
\end{tabular}

Table III. Electrochemical parameters (average (standard deviation)) determined from potentiodynamic polarization curves measured for the three dental alloys in aerated $0.9 \mathrm{wt} \% \mathrm{NaCl}$ solution.

\begin{tabular}{|l|c|c|}
\hline \multicolumn{1}{|c|}{ Dental alloy } & $E_{\text {corr }} / \mathrm{V}_{\mathrm{SCE}}$ & $j_{\text {corr }} / \mu \mathrm{A} \mathrm{cm}^{-2}$ \\
\hline Heraenium NA & $-0.223(0.00011)$ & $0.310(0.0126)$ \\
\hline Heraenium CE & $-0.728(0.00029)$ & $0.185(0.0027)$ \\
Paliag & $-0.182(0.00008)$ & $0.645(0.0313)$ \\
\hline
\end{tabular}



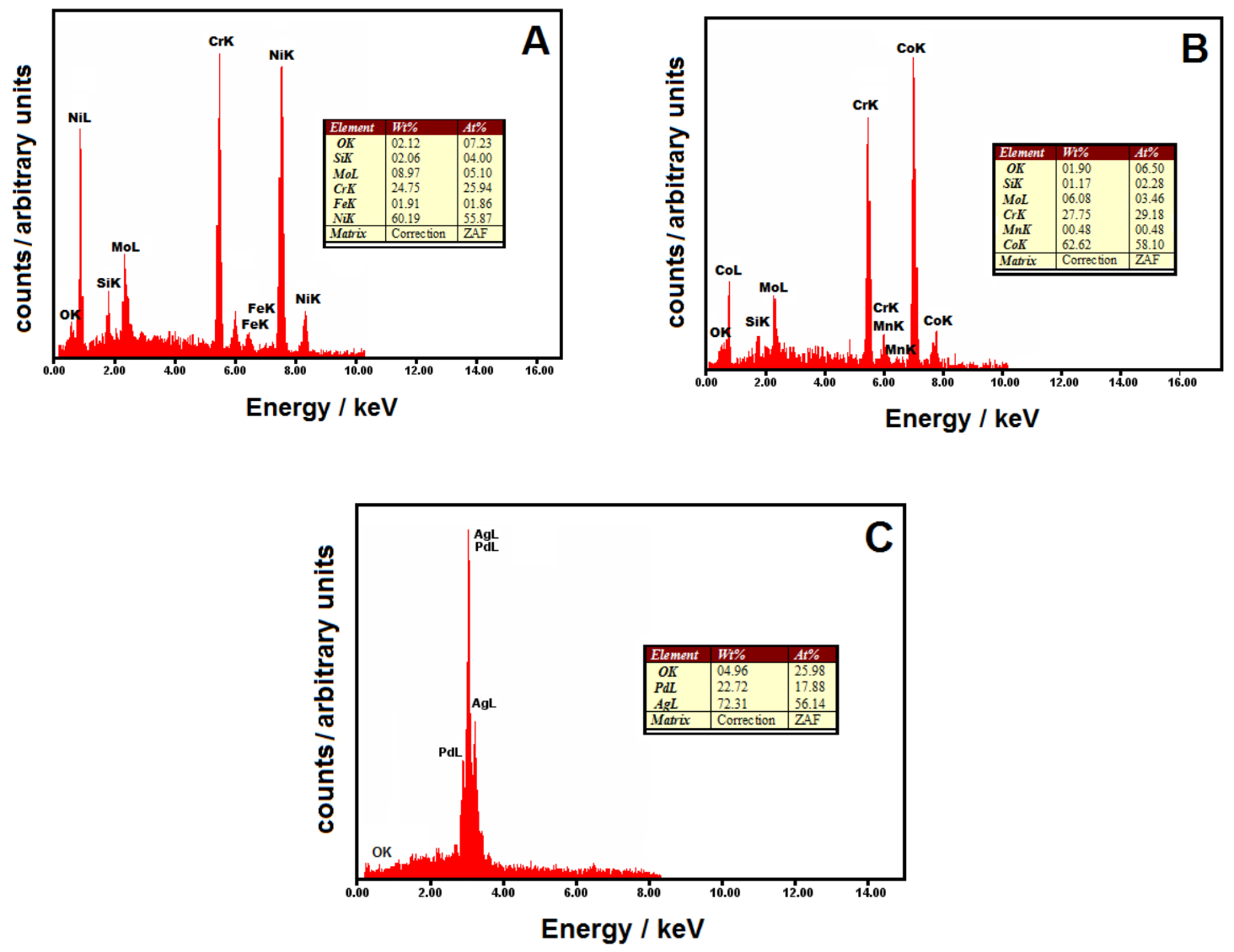

Figure 1. EDX survey spectra recorded at the surface of the dental alloys as received: (A) Heraenium NA, (B) Heraenium CE, and (C) Paliag samples. 

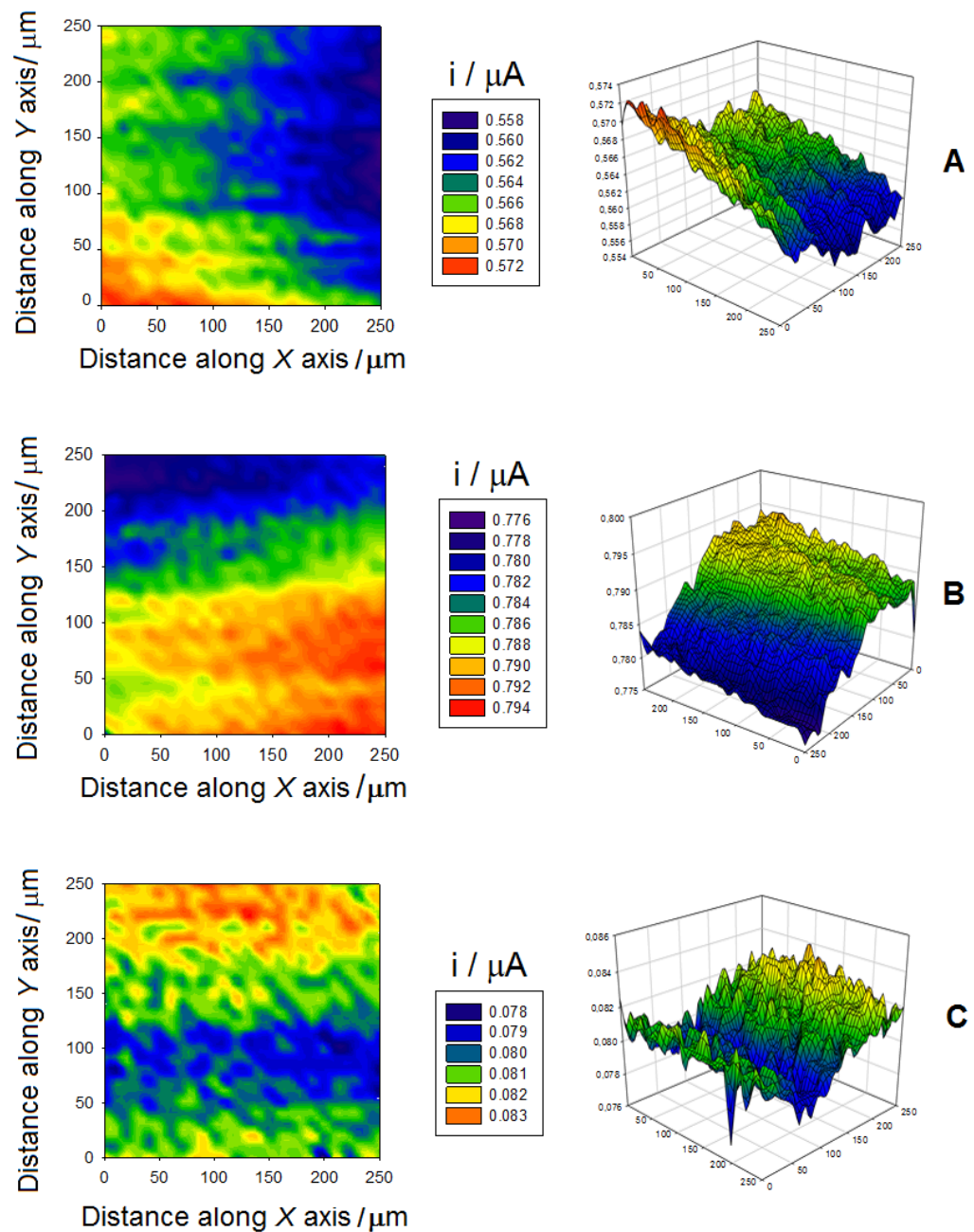

Figure 2. SECM images of: (A) Heraenium NA, (B) Heraenium CE, and (C) Paliag samples, maintained at their respective $E_{\text {corr, }}$ during immersion in $0.9 \mathrm{wt} . \% \mathrm{NaCl}+0.5 \mathrm{mM}$ ferrocene-methanol solution. Tip-substrate distance: $10 \mu \mathrm{m}$. 

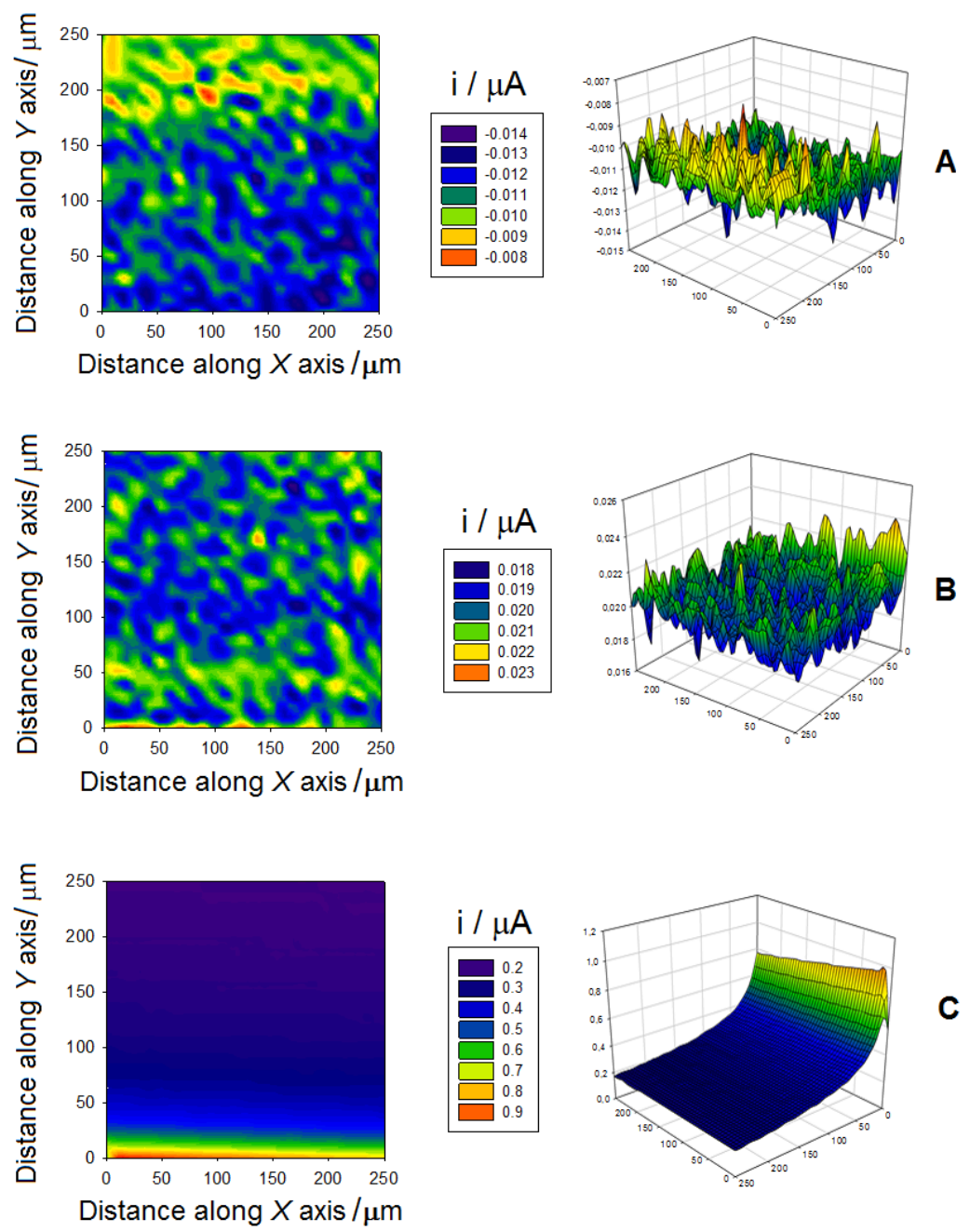

C

Figure 3. SECM images of: (A) Heraenium NA, (B) Heraenium CE, and (C) Paliag samples, polarized at $+0.4 \mathrm{VSCE}_{\mathrm{SC}}$ during immersion in $0.9 \mathrm{wt} . \% \mathrm{NaCl}+0.5 \mathrm{mM}$ ferrocene-methanol solution. Tip-substrate distance: $10 \mu \mathrm{m}$. 

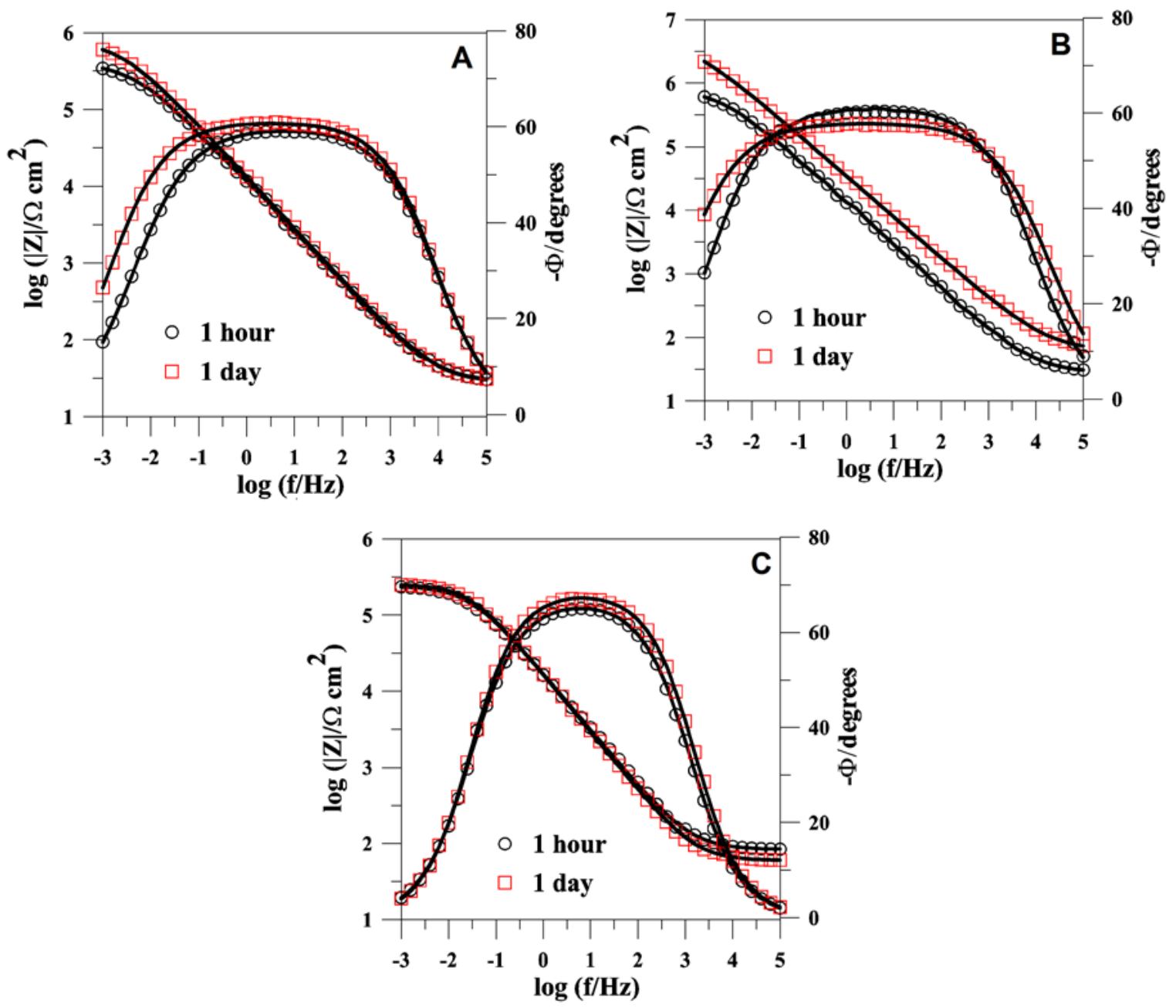

Figure 4. Measured (discrete points) and fitted (solid lines) Bode impedance spectra for the dental alloys recorded at their open circuit potentials during exposure to aerated 0.9 wt.\% $\mathrm{NaCl}$ solution for different time durations as indicated in the plot. Dental alloys: (A) Heraenium NA, (B) Heraenium CE, and (C) Paliag.
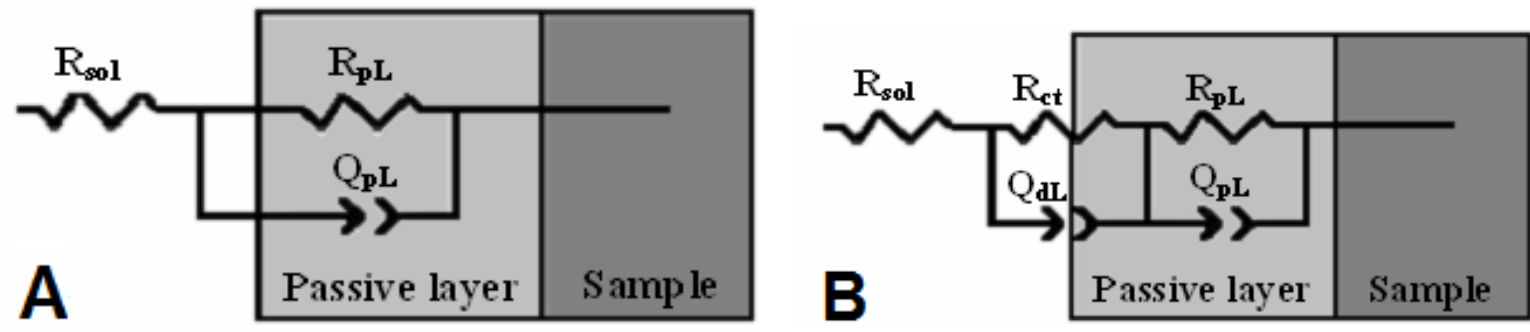

Figure 5. Equivalent circuits (EC) used in the generation of simulated data for the measured impedance spectra: (A) one-layer model of a barrier-type compact oxide surface film with one time constant; and (B) two-layer model of an unsealed porous surface film with two time constants. 


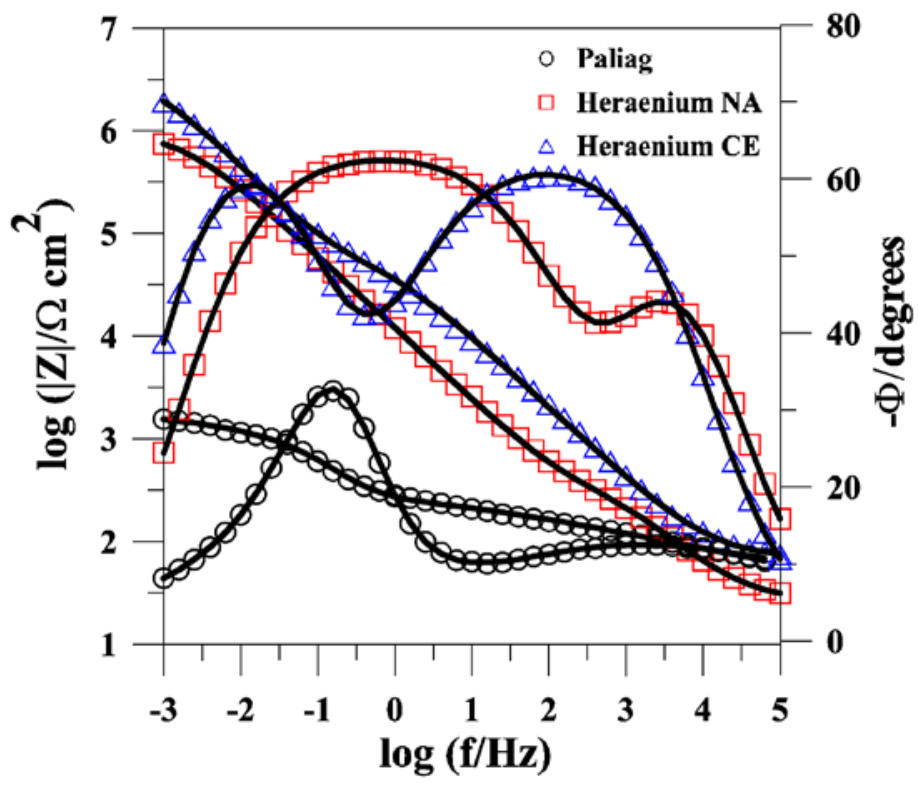

Figure 6. Measured (discrete points) and fitted (solid lines) impedance spectra typical of the dental alloys polarized at $+0.4 \mathrm{VSCE}$ during immersion in aerated $0.9 \mathrm{wt} . \% \mathrm{NaCl}$ solution.

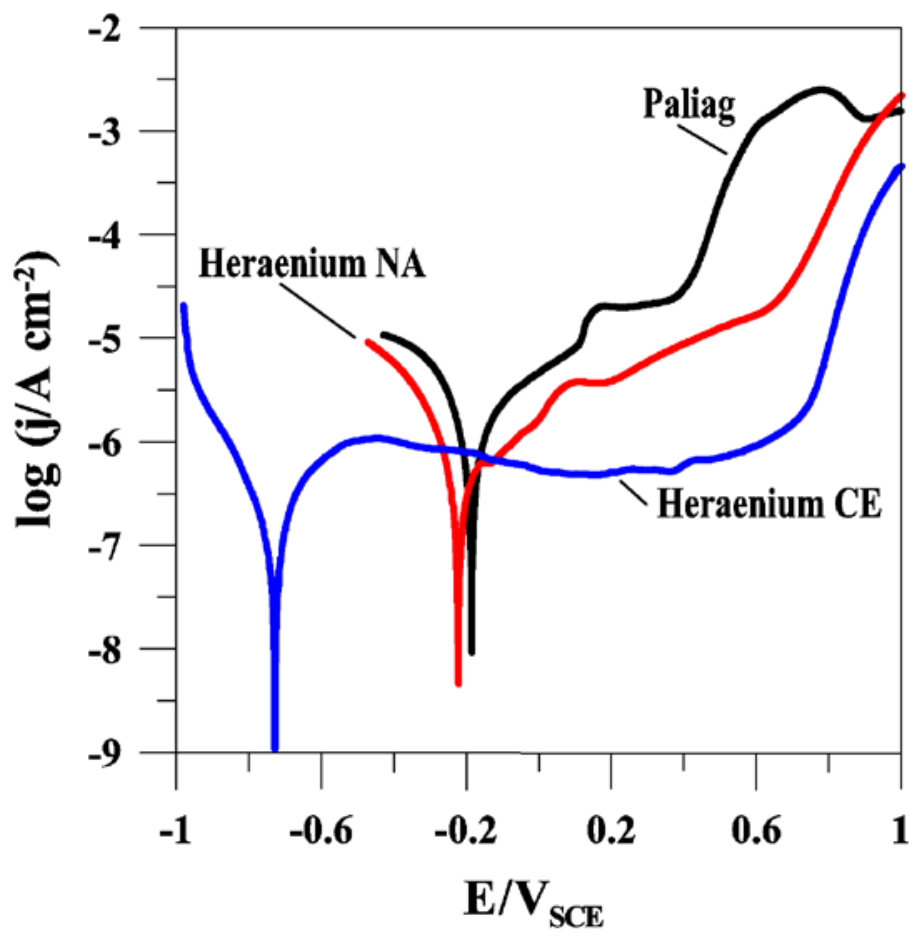

Figure 7. Polarization curves for the dental alloys in 0.9 wt.\% $\mathrm{NaCl}$ solution. Scan rate: $0.5 \mathrm{mV} \mathrm{s}{ }^{-1}$. 

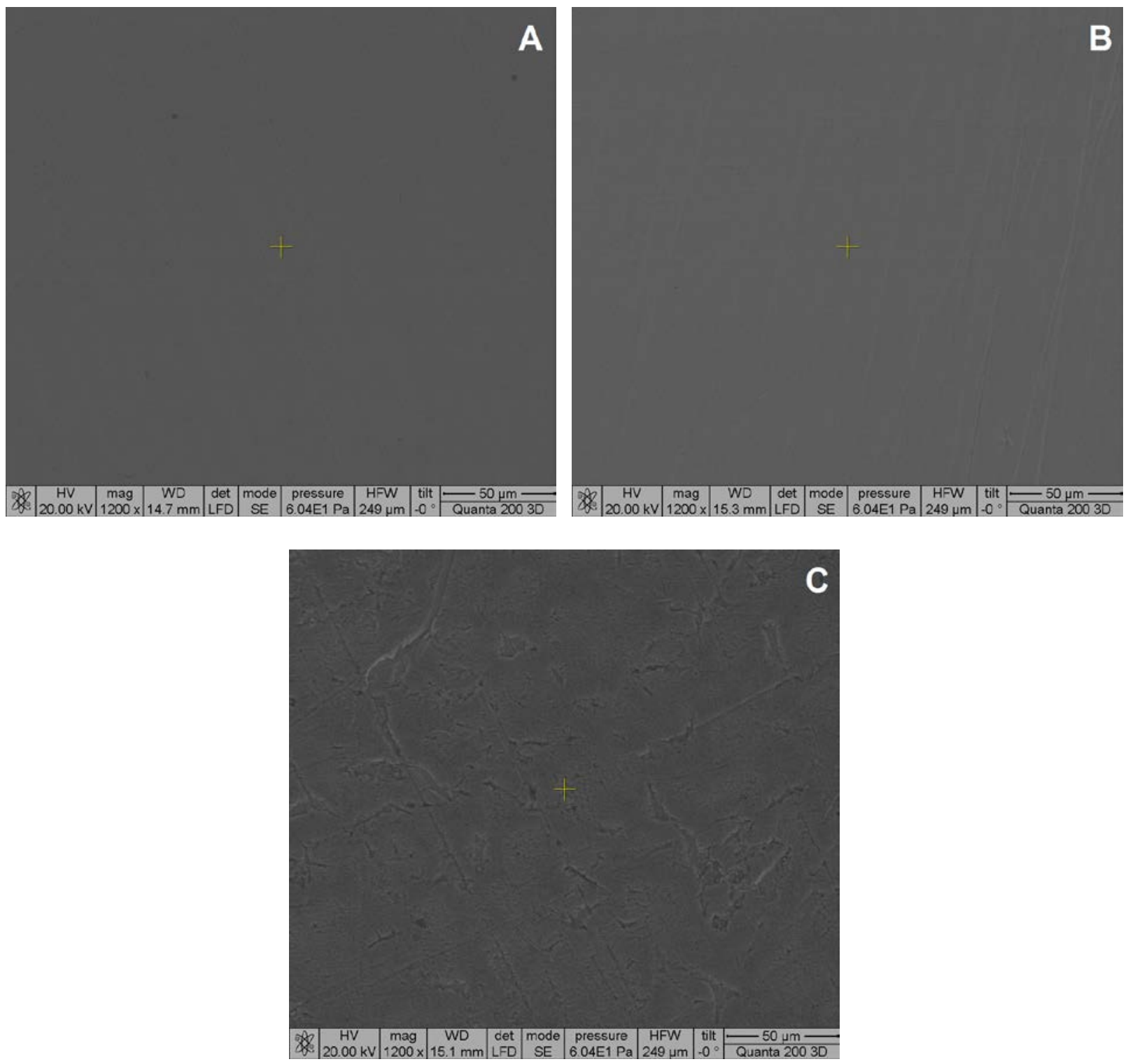

Figure 8. SEM micrographs showing the morphology of the surface attack morphology of: (A) Heraenium NA, (B) Heraenium CE, and (C) Paliag alloys, retrieved after anodic potentiodynamic polarization in aerated $0.9 \mathrm{wt} . \% \mathrm{NaCl}$ solution. 

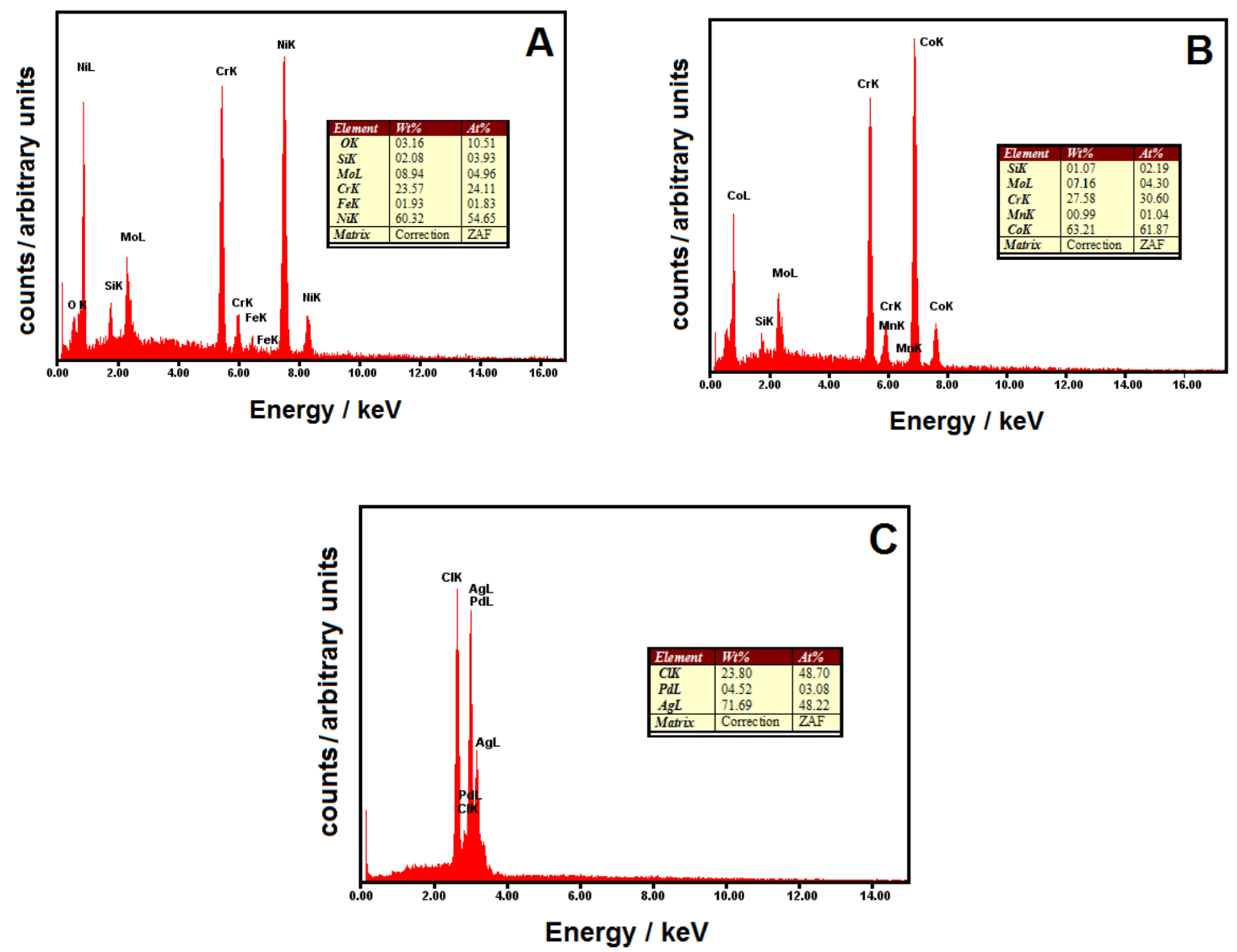

Figure 9. EDX survey spectra recorded at the surface of the dental alloys after anodic potentiodynamic polarization in aerated 0.9 wt.\% NaCl solution. Alloys: (A) Heraenium NA, (B) Heraenium CE, and (C) Paliag. 


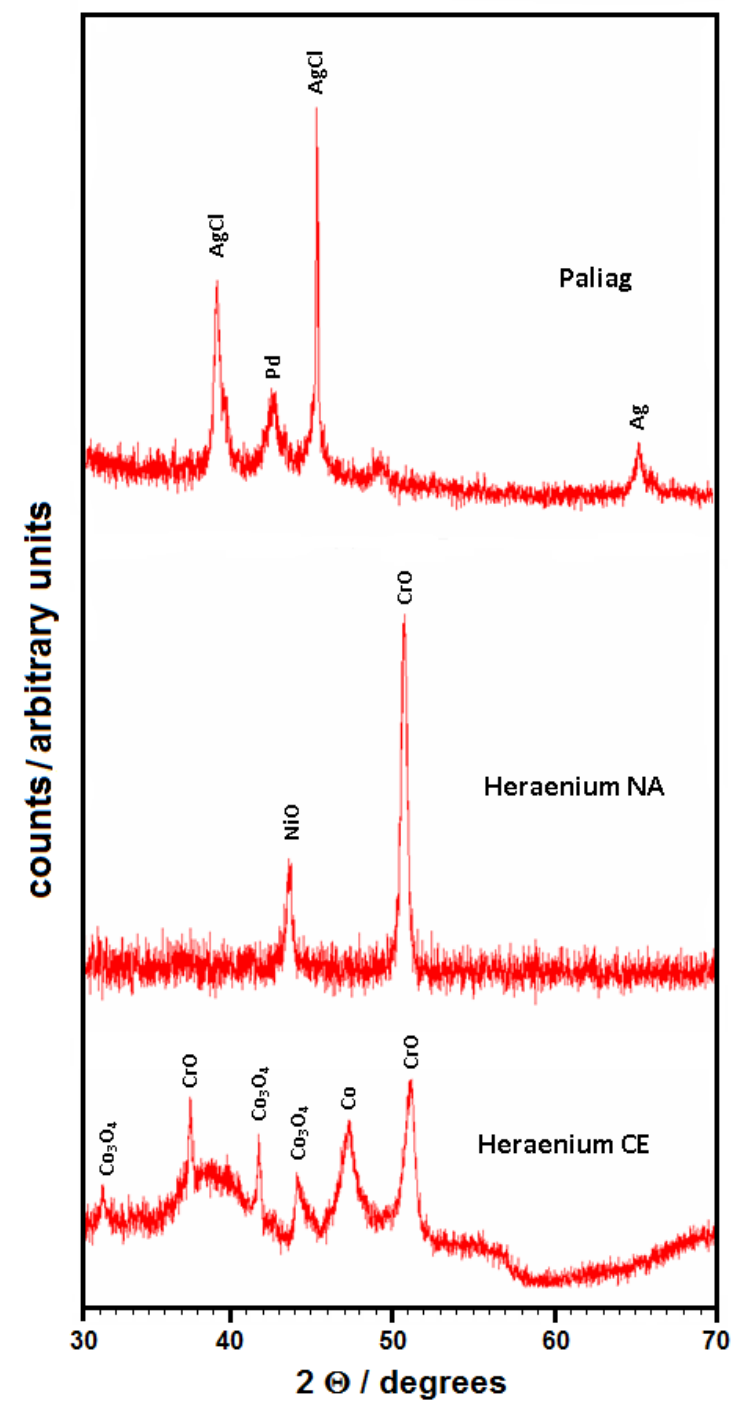

Figure 10. XRD patterns of the dental alloys Heraenium NA, Heraenium CE, and Paliag after anodic potentiodynamic polarization in aerated $0.9 \mathrm{wt} . \% \mathrm{NaCl}$ solution. 